\title{
Uniportal video-assisted thoracoscopic drainless sympathectomy for palmar and palmo-plantar hyperhidrosis: an institutional experience
}

\author{
Mohammed Ahmed El-Hag-Aly', Rafik Fekry Soliman', Nehad Abdo Zaid², Mahmoud Said Eldesouky², \\ Mohamed Mordy Bakoush ${ }^{1}$ and Mohamed Gamal Hagag ${ }^{1 *}$ (i)
}

\begin{abstract}
Background: Primary hyperhidrosis (PH) still impacts negatively the patient's quality of life (QoL). Progressively, it leads to poorer QoL regardless of gender. The endoscopic thoracic sympathectomy has been used safely and effectively for control of palmar hyperhidrosis, but it is still questionable in palmo-plantar type. We assessed the benefits of uniportal drainless thoracoscopic sympathectomy (UDTS) for palmo-plantar hyperhidrosis patients compared to palmar ones.

This prospective study comprised 213 consecutive patients with PH. They underwent bilateral simultaneous UDTS. We used the Hyperhidrosis Disease Severity Scale (HDSS) scoring system for assessment of QoL pre- and postoperatively. Follow-up was continued for 1-year that was aiming to detect the QoL improvement, recurrence, and compensatory hyperhidrosis $(\mathrm{CH})$.
\end{abstract}

Results: All patients experienced immediate complete resolution of hyperhidrosis postoperatively. Recurrence was encountered in one patient during the first 6 months. All patients had improved QoL postoperatively, but at the end of 1-year follow-up, 2.8\% of patients were still suffering moderate to severe impaired QoL. Mean hospital stay was $31.79 \pm 17.5 \mathrm{~h}$. We found significant longer hospital stay in palmar group than palmo-plantar group. There was no significant difference between both groups in neither operative time, recurrence, nor $\mathrm{CH}$.

Conclusions: UDTS offers better QoL for patients with PH even the palmo-plantar type. The palmo-plantar type benefits similarly to the palmar type in terms of comparable postoperative QoL and $\mathrm{CH}$ incidence.

Keywords: Hyperhidrosis, Sympathectomy, Thoracoscopy, Thoracic surgery, Video assisted

\section{Background}

Hyperhidrosis is a sweat glands' benign functional disorder. Usually, the hyperhidrosis patient presents by heat or emotional stimulated excessive sweating beyond the physiological needs. Moreover, it causes psycho-social and professional embracement that negatively impacts the quality of life (QoL) [1-3].

\footnotetext{
* Correspondence: mohamedhagag@med.menofia.edu.eg

${ }^{1}$ Cardiothoracic Surgery Department, Faculty of Medicine, Menoufia

University, Yassin Abdel Ghaffar Street, Shebin El-Kom, Menoufia, Egypt

Full list of author information is available at the end of the article
}

Hyperhidrosis may be primary or secondary. The etiology of primary hyperhidrosis $(\mathrm{PH})$ is still unknown. It affects about 0.6 to $1 \%$ in the general population. The most usual sites or domains of hyperhidrosis are the hands in $25 \%$ of cases, armpit in $20 \%$, both in $55 \%$, and plantar hyperhidrosis in $45 \%$ of cases [2, 4].

Management of those patients includes many medications as topical medication and botulinum toxin injection [5]. In 1920s, the trans-thoracotomy surgical treatment started to appear in medical practice with significant patient morbidity. It failed to generate

\section{Springer Open}

๑ The Author(s). 2020 Open Access This article is licensed under a Creative Commons Attribution 4.0 International License, which permits use, sharing, adaptation, distribution and reproduction in any medium or format, as long as you give appropriate credit to the original author(s) and the source, provide a link to the Creative Commons licence, and indicate if changes were made. The images or other third party material in this article are included in the article's Creative Commons licence, unless indicated otherwise in a credit line to the material. If material is not included in the article's Creative Commons licence and your intended use is not permitted by statutory regulation or exceeds the permitted use, you will need to obtain permission directly from the copyright holder. To view a copy of this licence, visit http://creativecommons.org/licenses/by/4.0/. 
widespread acceptance [6]. Evolving thoracoscopy approach enhanced the thoracoscopic sympathectomy to become the surgical technique of choice for treating $\mathrm{PH}$. This minimally invasive procedure is simple and safe, with a high success rate with low morbidity and short hospital stay [7]. Although, being an effective method for management of $\mathrm{PH}$, it has some complications such as compensatory hyperhidrosis $(\mathrm{CH})$, pneumothorax, Horner's syndrome, postoperative pain, and recurrence $[8,9]$.

We assessed the benefits of uniportal drainless thoracoscopic sympathectomy (UDTS) for palmo-plantar hyperhidrosis patients compared to palmar ones.

\section{Methods}

From April 2018 to August 2019, we enrolled in a prospective observational study 213 consecutive patients with a diagnosis of $\mathrm{PH}$. They underwent bilateral UDTS. Inclusion criteria were as follows: patients had bilateral $\mathrm{PH}$, no hormonal or electrolyte imbalances, failed medical treatment with different topical medication for 3 months, failed or refused botulinum toxin injection, and patients with Hyperhidrosis Disease Severity Scale (HDSS) [10] score of 3 or 4. Exclusion criteria included secondary hyperhidrosis and previous thoracic surgeries. Primary surgical outcome was set as improved HDSS score of $2^{\circ}$ at 1 -year follow-up, while secondary surgical outcomes were postoperative pain score, complications, hospital stay, residual pneumothorax, patients needing chest tube placement, and $\mathrm{CH}$ severely affecting QoL.

We managed the patients in the Cardiothoracic Surgery and Vascular Surgery departments in our institution. Our Institutional ethical committee approved data collection and waived the need for patient consent.
We used The HDSS scoring system (Table 1) to evaluate patient's QoL throughout the study. We included patients with severe QoL impairment; those are patients who scored 3 or 4 in the scale. They were managed by bilateral simultaneous UDTS. We operated the right side at first then the left one in the same session.

Anesthesiologist used general inhalational anesthesia through double lumen endotracheal tube. The latter allowed for single lung ventilation during the operation. The patients were positioned in $45^{\circ}$ anti-Trendelenburg supine position with both arms abducted at $90^{\circ}$; this enhanced that both sides could be operated on the same session without repositioning. It ended up with saving more time.

We operated through one skin incision $(12-15 \mathrm{~mm})$. In males, the incision was placed in the 3rd or 4th space at anterior axillary line; while in females, it was placed under mammary crease for cosmetic purpose. Through this single opening, we introduced $10-\mathrm{mm}$ camera (Karl Storz, Germany) and electrocautery endoscopic spatula (Karl Storz, Germany); no insufflator was required. We preferred the $10-\mathrm{mm}$ camera as its shaft is rigid enough to retract the lung in comparison to the $5-\mathrm{mm}$ camera which will be more fragile and may be scratched or spoiled during introduction of spatula with the $5-\mathrm{mm}$ camera through the same opening.

Parietal pleura, overlying the chain, was incised using electrocautery surgical unit (EMED "es350", Poland). The electrocautery unit was set at 40 degrees level of soft dissecting coagulation mode. Then, the sympathetic chain was divided by 5 -s continuous cautery at top and bottom of R2, R3, and R4 levels. The lateral aspect of each rib was cauterized for $1-2 \mathrm{~cm}$ to ensure a complete cut of any Kuntz's inter-neuronal connections. If the

Table 1 HDSS scoring system [10]

\section{Hyperhidrosis Disease Severity Scale}

'How would you rate the severity of your hyperhidrosis?'

$\square$ 1. My sweating is never noticeable and never interferes with my daily activities.

$\square$ 2. My sweating is tolerable but sometimes interferes with my daily activities

$\square$ 3. My sweating is barely tolerable and frequently interferes with my daily activities

4. My sweating is intolerable and always interferes with my daily activities

HDSS Score of 1: mild; HDSS Score of 2: moderate; HDSS Score of 3-4: severe. 
Kuntz Fibers were left uncut, it may cause failure of the sympathetic denervation.

At the end of the procedure, the anesthesiologist resumed the continuous positive pressure ventilation for both lungs. We observed the lung re-expansion again. One or two stitches were applied to close the port site; the other side was operated afterwards using the same technique.

All patients were extubated and transferred to the recovery room till achieving full recovery from anesthesia. Discharge criteria to ward were normal equality of air entry on both sides and normal oxygen saturation. We used either paracetamol or non-steroidal antiinflammatory drugs (NSAIDS) for pain control. We performed a chest $\mathrm{x}$-ray film to detect postoperative hemothorax or pneumothorax. We recorded neurological problems (as: Horner's syndrome) and hospital stay (in hours).

Follow-up in the outpatient clinic was at 1-week, 6month, and 1-year intervals after discharge. Every visit, we checked for improvement of QoL (using HDSS score), recurrence, $\mathrm{CH}$ (site and severity), and wound infection.

\section{Statistical analysis}

Collected data was expressed as mean and standard deviation $(\mathrm{M} \pm \mathrm{SD})$ or number and percent $(n, \%)$. Comparison between the two groups was performed using $t$ test, chi-square analysis $\left(\chi^{2}\right)$, or Fischer's exact test when appropriate. The data were considered significant if $P$ value was less than 0.05 . Statistical analysis was performed using IBM Statistical Package for Social Science (SPSS) version 20 (IBM corporation, Chicago, IL, USA).

\section{Results}

We operated 213 patients (61.5\% females) using UDTS. They were $20.83 \pm 4.12$ years old. Seventy-nine (37.1\%) patients had plantar domain of hyperhidrosis. Patient's characteristics are enlisted in Table 2.

Average overall hospital stay was $31.79 \pm 17.5 \mathrm{~h}$ entailing the whole patient's stay within the hospital from admission till discharge. Unfortunately, some patients suffered few complications (Table 3) as pneumothorax in $6(2.8 \%)$ patients from which $2(0.9 \%)$ patients only required intercostal chest tube (ICT) insertion. No Horner's syndrome cases, wound infection, nor mortality were encountered in our series. The mean follow-up period for the overall cohort was $13.56 \pm 1.11$ months.

Starting from the 6-month follow-up visit, our patients began to complain of $\mathrm{CH}$; the overall incidence was $35.7 \%$ of patients. Domains and percentages are grouped in Table 3. Moreover, we had one patient $(0.5 \%)$ presented with recurrence. He refused to undergo a redo procedure again because it was affecting his left non-
Table 2 Patient preoperative characteristics

\begin{tabular}{ll}
\hline Variable & $n=213$ \\
\hline Age, mean \pm SD & $20.83 \pm 4.12$ \\
Sex, $n(\%)$ & \\
$\quad$ Male & $82(38.5 \%)$ \\
$\quad$ Female & $131(61.5 \%)$ \\
BMl, mean \pm SD & $23.1 \pm 2.9$ \\
Area/domain affected, $n(\%)$ & \\
Palmar & $213(100 \%)$ \\
Axillary & $101(47.4 \%)$ \\
Plantar & $79(37.1 \%)$ \\
Preoperative HDSS, $n(\%)$ & \\
3 & $118(55.4 \%)$ \\
4 & $95(44.6 \%)$ \\
\hline
\end{tabular}

BMI body mass index, HDSS Hyperhidrosis Disease Severity Scale

dominant limb, so according to his words "it is not affecting my daily life to force me for surgery again."

All patients experienced immediate complete resolution of hyperhidrosis postoperatively; however, 1 $(0.5 \%)$ patient was still suffering severe impaired QoL at 6 months in comparison to $6(2.8 \%)$ patients at 1-year interval (Table 3).

Table 3 Procedure data

\begin{tabular}{ll}
\hline Variable & $n=213$ \\
\hline Operative time (minutes), mean \pm SD & $35.03 \pm 4.1$ \\
Hospital stay (hours), mean \pm SD & $31.79 \pm 17.5$ \\
Postoperative pneumothorax, $n(\%)$ & $6(2.8 \%)$ \\
Postoperative ICT, $n$ (\%) & $2(0.9 \%)$ \\
Duration of follow-up (months), mean \pm SD & $13.56 \pm 1.11$ \\
Compensatory hyperhidrosis (CH), $n(\%)$ & $76(35.7 \%)$ \\
Areas/domains affected by CH, $n(\%)$ & \\
Palmar & $1(0.5 \%)$ \\
Axillary & $1(0.5 \%)$ \\
Plantar & $30(14.1 \%)$ \\
Facial & $1(0.5 \%)$ \\
Trunkal & $75(35.2 \%)$ \\
Recurrence & $1(0.5 \%)$ \\
Postoperative HDSS score at 6 months & \\
1 & $212(99.5 \%)$ \\
3 & $1(0.5 \%)$ \\
Postoperative HDSS score at 1 year & \\
1 & $200(93.9 \%)$ \\
3 & $7(3.3 \%)$ \\
\hline
\end{tabular}

ICT intercostal chest tube, HDSS Hyperhidrosis Disease Severity Scale 
Ten $(4.7 \%)$ patients did not achieve the primary outcome, and their QoL did not improve $2^{\circ}$ at 1-year follow-up; consequently, they were excluded from further analysis.

On comparing the 75 (36.95\%) patients with plantar domain (palmo-plantar group) to the remaining patients (palmar group) in the study group (Table 4), we detect significant longer hospital stay in palmar group. On the other side, we got no significant difference between both groups in operative time, recurrence, $\mathrm{CH}$ (percent and domains), nor postoperative HDSS score at 6-month and 1-year intervals.

\section{Discussion}

Currently, the endoscopic thoracic sympathectomy is accepted as a standard treatment technique for $\mathrm{PH}$. This minimally invasive approach has many benefits as reducing postoperative pain, shorter hospitalization, earlier recovery and return to work, and fewer complications. Both sides can be treated in the same sitting, thus avoiding readmission for a second procedure for the opposite side [11].
This thoracoscopic approach allows clear delineation of the sympathetic chain and the ganglia including the collateral branches (Kuntz's nerves). Also, it allows for better visualization of the stellate ganglion and its preservation to avoid development of postoperative Horner's syndrome [12].

The initial history of the uniportal video-assisted thoracoscopic surgery had started from the results of the first prospective trial reporting the method to perform several thoracic procedures via $2-\mathrm{cm}$ uniportal technique; it was initiated in 1998 and published in 2000 [13], 2001 [14], and 2003 [15]. The two most common limitations for the 2-cm uniportal technique are the crowding of surgical instruments that collide with one another and the optic that gets dirty easily [16].

The more cosmetic and interesting needlescopic sympathectomy, which was reported 20 years ago by Yamamoto et al. [17], did not gain popularity in practice or publications. Yamamoto et al., in their next publication in 2017, noted that "Only one article, which was authored by us, reported on the needlescopic technique through a single skin incision. The appliance had to be pulled out to enable use of a different shape. With the

Table 4 Palmar versus palmo-plantar outcome

\begin{tabular}{|c|c|c|c|}
\hline Variable & Palmar $(n=128)$ & Palmo-plantar $(n=75)$ & $P$ value \\
\hline Age, mean $\pm S D$ & $21.16 \pm 3.79$ & $20.6 \pm 4.53$ & 0.34 \\
\hline \multicolumn{4}{|l|}{ Sex, $n(\%)$} \\
\hline Male & $50(39.1 \%)$ & $30(40 \%)$ & \multirow[t]{2}{*}{1} \\
\hline Female & $78(60.9 \%)$ & $45(60 \%)$ & \\
\hline $\mathrm{BMI}$, mean $\pm \mathrm{SD}$ & $23.65 \pm 3.29$ & $22.21 \pm 2$ & 0.001 \\
\hline \multicolumn{4}{|l|}{ Preoperative HDSS score, $n(\%)$} \\
\hline 3 & $68(53.1 \%)$ & $42(56 \%)$ & \multirow[t]{2}{*}{0.77} \\
\hline 4 & $60(46.9 \%)$ & $33(44 \%)$ & \\
\hline Operation time, mean \pm SD & $35.59 \pm 3.99$ & $34.35 \pm 4.02$ & 0.03 \\
\hline Hospital stay, mean \pm SD & $35.38 \pm 21.26$ & $26.07 \pm 4.55$ & 0.001 \\
\hline Pneumothorax, $n(\%)$ & $6(4.7 \%)$ & 0 & 0.08 \\
\hline $\mathrm{ICT}, n(\%)$ & $2(1.6 \%)$ & 0 & 0.53 \\
\hline Compensatory hyperhidrosis $(\mathrm{CH}), n(\%)$ & $41(32 \%)$ & $26(34.7 \%)$ & 0.76 \\
\hline \multicolumn{4}{|l|}{ Areas affected by $\mathrm{CH}, n(\%)$} \\
\hline Palmar & 0 & 0 & \\
\hline Axillary & 0 & 0 & \\
\hline Plantar & $12(9.4 \%)$ & $9(12 \%)$ & 0.63 \\
\hline Facial & 0 & 0 & \\
\hline Trunkal & $40(31.3 \%)$ & $26(34.7 \%)$ & 0.64 \\
\hline \multicolumn{4}{|l|}{ Post-operative HDSS score at 6 months, $n(\%)$} \\
\hline 1 & $128(100 \%)$ & $75(100 \%)$ & \\
\hline \multicolumn{4}{|l|}{ Post-operative HDSS score at 1 year, $n(\%)$} \\
\hline 1 & $127(99.2 \%)$ & $73(97.3 \%)$ & \multirow[t]{2}{*}{0.56} \\
\hline 2 & $1(0.8 \%)$ & $2(2.7 \%)$ & \\
\hline
\end{tabular}

BMI body mass index, ICT intercostal chest tube, HDSS Hyperhidrosis Disease Severity Scale 
previous technique, a sharp tip device could not be inserted. Mobilization, separation, and extraction were not possible with the previous technique." Furthermore, they expected that the new 2017 device would not be popular also; they reported that "some difficulties in the use of the new device include shortage of strength and unsuitability for complicated structures because of its joints and limited diameter. Parts of the appliance falling off might become a serious medical accident" [18].

Our study included 213 patients diagnosed as $\mathrm{PH}$ and managed by UDTS. They had immediate improvement of hyperhidrosis without any mortality. There was no need for the placement of any additional ports. We had no conversions to open thoracotomy in our series.

Mean BMI in our study was $23.1 \pm 2.9$. This is going similarly with Woloske et al.'s [19] study who reported mean BMI of $20.6 \pm 3$ and $21.9 \pm 2.55$ for their adolescent and adult groups. Miller et al. [20], in their study of 282 patients, found that increased BMI was associated with increased $\mathrm{CH}$. Patients with higher BMI have more difficulty with their thermoregulation.

Using the HDSS scoring for selecting patients, the patients who scored 3 were $55.4 \%$ of study patients and those who scored 4 were $44.6 \%$. Postoperatively, at 1 year follow-up, dramatic improvement of patients' QoL was achieved. Our patients' HDSS score was changed to 93.9\% mild and $6.1 \%$ moderate to severe. This was quite the same as Kuijpers et al. [21]; in their study including 100 patients with bilateral thoracoscopic sympathectomy, they reported significant improvement of HDSS score with mean preoperative HDSS score of $3.69 \pm 0.47$ and mean postoperative HDSS of $1.06 \pm 0.34$. This emphasizes that UDTS is an effective line in management of PH with improved QoL.

Despite that dramatic improvement in QoL, we noticed the occurrence of $\mathrm{CH}$. It manifests as excessive sweating in different areas of body appearing later after completely free interval of any excessive sweating. In our study, most of them were after 6 months; its overall incidence was $35.7 \%$ of patients. This is still the most common late complication, although its mechanism is still unclear.

$\mathrm{CH}$ after thoracoscopic sympathectomy has been previously explained as a thermoregulatory response to the anhidrosis induced by the sympathectomy. It is doubtful, however, that the large quantity of sweat observed in $\mathrm{CH}$ aids in body temperature control. There is vast evidence to indicate that there is a nerve system emitting a large quantity of sudomotor signaling to the skin where $\mathrm{CH}$ appears. Interrupting one of the nerve circuits related to $\mathrm{CH}$ could result in $\mathrm{CH}$ being ameliorated; however, it has proved difficult to detect precisely where the nerve circuitry is located [22].
The incidence of $\mathrm{CH}$ in our study was lower than that of Prasad et al.'s [23] study. They had CH incidence of $63 \%$ postoperatively after R3 resection. Ibrahim et al. [24], who resected from R2 to R4, reported that $19 \%$ of their patients got $\mathrm{CH}$ and showed a gradually decreasing intensity over the follow-up period.

Our lower incidence of $\mathrm{CH}$ may be due to adding the cauterization of R2 with lateral extension of cauterization for $2 \mathrm{~cm}$ at every level that ensured good control of early migrating fibers of Kuntz nerves. The latter is usually claimed for the $\mathrm{CH}$. The other contributing factor to lower $\mathrm{CH}$ incidence may be the cauterization at upper and lower margins of every level.

The UDTS procedure required an operative time of 20 45 min with mean of $35.03 \pm 4.1 \mathrm{~min}$. Nearly, Ibrahim et al. [24], who operated 260 patients with single-stage bilateral thoracoscopic sympathectomy, reported a mean operating time of $38 \pm 5.0 \mathrm{~min}$. On the other side, Kuijpers et al. [21] got a mean operative time of $74 \pm 12 \mathrm{~min}$ for a bilateral sympathectomy. Kuijpers et al. [21] used to perform their operation in lateral decubitus position, so more time was consumed in patient repositioning. When they changed the patient's positioning to beach chair position, they could perform the surgery on both sides without the need for repositioning. This modification saved more time and showed significant reduction in their operation time to $47 \pm 18 \min (p<0.001)$.

Post-UDTS pain was tolerable; it required only oral paracetamol or NSAIDs. No patient needed morphine. The UDTS approach causes less postoperative pain as post-thoracoscopic pain is usually related to the trauma of the thoracic wall caused by introducing the trocars into the intercostal space and periosteal injury.

Concerning the importance of the palmo-plantar type, the plantar domain affects considerable part (about 45\%) of those patients with $\mathrm{PH}$ [4]. Other studies reported incidence of plantar domain of 70 to $100 \%$ in patients with $\mathrm{PH}$; the latter researchers used extended technique of ablation from R3 to R12 to manage those cases [25]. In the Society of Thoracic Surgeons 2011 Expert Consensus for the Surgical Treatment of Hyperhidrosis [26], no recommendations for plantar domain management were noted. All the previous reasons aroused us to study the plantar type of hyperhidrosis patients using a less invasive technique and searching for acceptable outcome.

On comparing the palmo-plantar patients to palmar ones, we found comparable groups with no significant difference regarding age, sex distribution, preoperative HDSS score, pneumothorax, or recurrence.

Mean hospital stay was $35.38 \pm 21.26 \mathrm{~h}$ in palmar group. It was significantly longer than the mean hospital stay in palmo-plantar group that was $26.07 \pm 4.55 \mathrm{~h}$ ( $p=$ 0.001 ). That longer stay may be due to higher rate of 
pneumothorax (4.7\%) and intercostal tube insertion $(1.6 \%)$ in the palmar group.

Regarding $\mathrm{CH}$ incidence, it was not significant between the two groups (32\% in palmar group and $34.7 \%$ in palmo-plantar group). Moreover, its distribution was not significant; the most common site was trunkal region followed by plantar region. Precisely, the plantar $\mathrm{CH}$ incidence was $9.4 \%$ in palmar group. This was nearly like the $\mathrm{CH}$ incidence of $12 \%$ in palmo-plantar group. This similar incidence is enforcing the hypothesis that patients with palmo-plantar hyperhidrosis would benefit from UDTS.

At last, the overall outcome was satisfactory. The patients' HDSS score at 1-year follow-up was 1 (mild) in 99.2\% of palmar group patients and $97.3 \%$ of palmoplantar ones. Even with the suffering of $\mathrm{CH}$, it still affects the QoL less than $\mathrm{PH}$. The reported $\mathrm{CH}$ in our series was mild and much less affecting the professional or social life of our patients.

Overtime, the researchers are still trying to provide more options for managing the $\mathrm{CH}$. This future solutions for $\mathrm{CH}$ will allow us to provide more UDTS procedures for PH patients. One of that promising trials is the use of intraoperative monitoring with laser speckle flowgraphy (LSFG) to indicate the causative ganglion of the $\mathrm{CH}$. Ganglionectomy was then performed [22]. It is a very good technique but expensive. The cost of LSFG is about US\$30,000.00. Weksler [27] commented to the report of LSFG technique saying that "the case report lacks some details that would be helpful to others attempting to duplicate the results. Specific parameters used for ganglia stimulation during laser speckle flow graphing, including voltage and duration, are not reported, and it is not clear what precautionary measures Yamamoto and Okada [22] took preoperatively and intraoperatively to ensure that the identified ganglia were, in fact, responsible for the $\mathrm{CH}$. Yamamoto and Okada [22] also did not comment on the presence or absence of any undesirable side effects of the procedure. Larger studies are needed to define clearly the efficacy of this procedure and its reproducibility." Ongoing studies and researches everywhere keep on trying to help $\mathrm{CH}$ patients, and that provides the light at the end of the tunnel for those patients.

\section{Conclusion}

UDTS offers better QoL for patients with PH even the palmo-plantar type. The palmo-plantar type benefits similarly to the palmar type in terms of comparable postoperative $\mathrm{QoL}$ and $\mathrm{CH}$ incidence.

\section{Abbreviations}

$\mathrm{CH}$ : Compensatory hyperhidrosis; HDSS: Hyperhidrosis Disease Severity Scale; ICT: Intercostal chest tube; NSAIDS: Non-steroidal anti-inflammatory drugs; PH: Primary hyperhidrosis; QoL: Quality of life; UDTS: Uniportal drainless thoracoscopic sympathectomy

\section{Acknowledgements}

Not applicable.

\section{Authors' contributions}

All authors have read and approved the manuscript. They were all involved in conceptualization, investigation, methodology, resources, and visualization. $\mathrm{RS}$ and $\mathrm{NZ}$ were involved in project administration. MAE, RS, NZ, and $\mathrm{MH}$ were involved in supervision and review and editing of the writing. MAE, $M S E, M B$, and $M H$ were involved in data curation, formal analysis, software, validation, and writing the original draft.

\section{Funding}

This research did not receive any specific grant from funding agencies in the public, commercial, or not-for-profit sectors.

\section{Availability of data and materials}

The datasets used and/or analyzed during the current study are available from the corresponding author on reasonable request

\section{Ethics approval and consent to participate}

Our institutional IRB, named The Ethical committee of Menoufia Faculty of Medicine, approved data collection (SURG 03/2018) and waived the need for patient consent.

\section{Consent for publication}

Not applicable.

\section{Competing interests}

The authors declare that they have no competing interests.

\section{Author details}

${ }^{1}$ Cardiothoracic Surgery Department, Faculty of Medicine, Menoufia University, Yassin Abdel Ghaffar Street, Shebin El-Kom, Menoufia, Egypt. ${ }^{2}$ Vascular Surgery Department, Faculty of Medicine, Menoufia University, Yassin Abdel Ghaffar Street, Shebin El-Kom, Menoufia, Egypt.

Received: 26 June 2020 Accepted: 30 August 2020

Published online: 11 September 2020

\section{References}

1. Wolosker N, Munia MA, Kauffman P, Campos JR, Yazbek G, Puech-Leão P (2010) Is gender a predictive factor for satisfaction among patients undergoing sympathectomy to treat palmar hyperhidrosis? Clinics (Sao Paulo) 65(6):583-586. https://doi.org/10.1590/S1807-59322010000600004

2. Gossot D, Kabiri H, Caliandro R, Debrosse D, Girard P, Grunenwald D (2001) Early complications of thoracic endoscopic sympathectomy: a prospective study of 940 procedures. Ann Thorac Surg 71(4):1116-1119. https://doi.org/ 10.1016/50003-4975(01)02422-5

3. Hajjar WM, Al-Nassar SA, Al-Sharif HM, Al-Olayet DM, Al-Otiebi WS, Al-Huqayl AA et al (2019) The quality of life and satisfaction rate of patients with upper limb hyperhidrosis before and after bilateral endoscopic thoracic sympathectomy. Saudi J Anaesth 13(1):16-22. https://doi.org/10.4103/sja. SJA_335_18

4. Karmota AG, Aboollo MF, Hafez BA, Shaker AA, Ghoneim B (2018) Prospective randomized study comparing video assisted thoracoscopic surgery (VATS) resection versus cautery for treatment of primary hyperhidrosis. J Egypt Soc Cardiothorac Surg 26:318-323. https://doi.org/10. 1016/j.jescts.2018.11.005

5. Dumont P, Denoyer A, Robin P (2004) Long-term results of thoracoscopic sympathectomy for hyperhidrosis. Ann Thorac Surg 78(5):1801-1807. https://doi.org/10.1016/j.athoracsur.2004.03.012

6. Dewey TM, Herbert MA, Hill SL, Prince SL, Mack MJ (2006) One-year followup after thoracoscopic sympathectomy for hyperhidrosis: outcomes and consequences. Ann Thorac Surg 81(4):1227-1232; discussion 1232-3. https:// doi.org/10.1016/j.athoracsur.2005.11.006

7. Chung $\mathrm{H}$, Oh CS, Koh KS, Kim HJ, Paik HC, Lee DY (2002) Anatomic variations of the T2 nerve root (including the nerve of Kuntz) and their implications for sympathectomy. J Thorac Cardiovasc Surg 123(3):498-501. https://doi.org/10.1067/mtc.2002.119340

8. Youssef T, Soliman M (2015) Unilateral sequential endoscopic thoracic sympathectomy for palmar hyperhidrosis: a proposed technique to 
overcome compensatory hyperhidrosis and improve plantar hyperhidrosis. J Laparoendosc Adv Surg Tech A 25(5):370-374. https://doi.org/10.1089/lap. 2014.0620

9. Romero FR, Haddad GR, Miot HA, Cataneo DC (2016) Palmar hyperhidrosis: clinical, pathophysiological, diagnostic and therapeutic aspects. An Bras Dermatol 91(6):716-725. https://doi.org/10.1590/abd1806-4841.20165358

10. Schieman C, Gary J, Gelfand GJ, Grondin SC (2010) Hyperhidrosis: clinical presentation, evaluation and management. Expert Rev Dermatol 5(1):31-44. https://doi.org/10.1586/edm.09.61

11. Du X, Zhu X, Wang T et al (2018) Compensatory hyperhidrosis after different surgeries at the same sympathetic levels: a meta-analysis. Ann Transl Med 6(11):203. https://doi.org/10.21037/atm.2018.05.24

12. Vannucci F, Araújo JA (2017) Thoracic sympathectomy for hyperhidrosis: from surgical indications to clinical results. J Thorac Dis 9(Suppl 3):S178S192. https://doi.org/10.21037/jtd.2017.04.04

13. Migliore M, Giuliano R, Deodato G (2000) Video assisted thoracic surgery through a single port. In: Thoracic surgery and interdisciplinary symposium on the threshold of the third millennium. An international continuing medical education programme, Naples, pp 29-30 Available online: http:// xoomer.virgilio.it/naples2000/index1.html. Accessed 14 Aug 2020

14. Migliore M, Deodato G (2001) A single-trocar technique for minimallyinvasive surgery of the chest. Surg Endosc 15:899-901. https://doi.org/10. $1007 / 5004640090033$

15. Migliore M (2003) Efficacy and safety of single-trocar technique for minimally invasive surgery of the chest in the treatment of noncomplex pleural disease. J Thorac Cardiovasc Surg 126:1618-1623. https://doi.org/10. 1016/s0022-5223(03)00592-0

16. Migliore M, Calvo D, Criscione A, Borrata F (2015) Uniportal video assisted thoracic surgery: summary of experience, mini-review and perspectives. $J$ Thorac Dis 7(9):E378-E380. https://doi.org/10.3978/j.issn.2072-1439.2015.07.35

17. Yamamoto H, Kanehira A, Kawamura M, Okada M, Ohkita Y (2000) Needlescopic surgery for palmar hyperhidrosis. J Thorac Cardiovasc Surg 120(2):276-279. https://doi.org/10.1067/mtc.2000.107830

18. Yamamoto H, Okada M (2017) A new device of needlescopic thoracic sympathectomy through a skin incision. Ann Thorac Surg 103:e465-e467. https://doi.org/10.1016/j.athoracsur.2016.11.068

19. Wolosker N, Faustino CB, de Campos JRM et al (2020) Comparative analysis of the results of videothoracoscopic sympathectomy in the treatment of hyperhidrosis in adolescent patients. J Pediatr Surg 55(3):418-424. https:// doi.org/10.1016/j.jpedsurg.2019.11.004

20. Miller DL, Bryant AS, Force SD, Miller JI Jr (2009) Effect of sympathectomy level on the incidence of compensatory hyperhidrosis after sympathectomy for palmar hyperhidrosis. J Thorac Cardiovasc Surg 138(3):581-585. https:// doi.org/10.1016/j.jtcvs.2009.03.059

21. Kuijpers M, Klinkenberg TJ, Bouma W, DeJongste MJ, Mariani MA (2013) Single-port one-stage bilateral thoracoscopic sympathicotomy for severe hyperhidrosis: prospective analysis of a standardized approach. J Cardiothorac Surg 8:216. https://doi.org/10.1186/1749-8090-8-216

22. Yamamoto H, Okada M (2019) The management of compensatory sweating after thoracic sympathectomy. J Thorac Cardiovasc Surg 158:1481-1488. https://doi.org/10.1016/j.jtcvs.2019.05.062

23. Prasad A, Ali M, Kaul S (2010) Endoscopic thoracic sympathectomy for primary palmar hyperidrosis. Surg Endosc 24(8):1952-1957. https://doi.org/ 10.1007/s00464-010-0885-5

24. Ibrahim M, Menna C, Andreetti C et al (2013) Bilateral single-port sympathectomy: long-term results and quality of life. Biomed Res Int 2013: 348017. https://doi.org/10.1155/2013/348017

25. Elalfy K, Emile S, Elfeki H, Elmetwally A, Farag M, Gado W (2017) Sequential extended thoracoscopic sympathicotomy for palmo-axillo-plantar hyperhidrosis. Ann Thorac Surg 104(4):1200-1207. https://doi.org/10.1016/J. athoracsur.2017.04.035

26. Cerfolio RJ, De Campos JR, Bryant AS et al (2011) The Society of Thoracic Surgeons expert consensus for the surgical treatment of hyperhidrosis. Ann Thorac Surg 91(5):1642-1648. https://doi.org/10.1016/j.athoracsur.2011.01.105

27. Weksler $B(2017)$ Is there light at the end of the tunnel for patients with severe compensatory hyperhidrosis? J Thorac Cardiovasc Surg 154(6):e117. https://doi.org/10.1016/j.jtcvs.2017.08.054

\section{Publisher's Note}

Springer Nature remains neutral with regard to jurisdictional claims in published maps and institutional affiliations.

\section{Submit your manuscript to a SpringerOpen ${ }^{\circ}$ journal and benefit from:}

- Convenient online submission

- Rigorous peer review

- Open access: articles freely available online

- High visibility within the field

- Retaining the copyright to your article

Submit your next manuscript at $\boldsymbol{\nabla}$ springeropen.com 